\title{
Stanford's Unconceived Alternatives from the Perspective of Epistemic Obligations
}

\author{
Matthew Sample \\ sample@uw.edu
}

\begin{abstract}
Kyle Stanford's reformulation of the problem of underdetermination has the potential to highlight the epistemic obligations of scientists. Stanford, however, presents the phenomenon of unconceived alternatives as a problem for realists, despite critics' insistence that we have contextual explanations for scientists' failure to conceive of their successors' theories. I propose that responsibilist epistemology and the concept of "role oughts," as discussed by Lorraine Code and Richard Feldman, can pacify Stanford's critics and reveal broader relevance of the "new induction." The possibility of unconceived alternatives pushes us to question our contemporary expectation for scientists to reason outside of their historical moment.
\end{abstract}


Copyright Philosophy of Science 2015

Preprint (not copyedited or formatted)

Please use DOI when citing or quoting

\section{Introduction}

Philosophical discussions of the problem of underdetermination have shifted and multiplied over time. At least as early as Duhem's invocation of "good sense," there have been different ways to conceive of underdetermination and its implications for scientific reasoning. Kyle Stanford traces some of these different threads back through philosophical history, dividing the problem into two versions, contrastive and holist. The former type of underdetermination, he explains, focuses on the interconnectedness of beliefs (which may be confirmed or not by some evidence), while the latter reminds us of the possibility that we might sometimes be faced with empirically equivalent theories (Stanford 2013). Thus, two related problems emerge for scientific reasoning, each with its own grounding and implications.

Stanford's book, Exceeding Our Grasp (2006) represents one of the more recent attempts to update our understanding of one form of underdetermination, to make it relevant to current discourse in philosophy of science. Frustrated with the state of current arguments for contrastive underdetermination - many of them reduce to radical skepticism-Stanford proposes a "new induction" across the history of science. The conclusion: we can't be sure that our current best theories are well-confirmed by the evidence, since we might fail to conceive of scientifically serious alternative theories. This finding is meant to be quite troubling to scientific realists, even those who insist that Stanford has ignored the contextual character of scientific reasoning.

But the "new induction" for contrastive underdetermination, I will argue, is relevant beyond debates over realism and the truth of our best theories. By forcing us to recognize the epistemic limitations of historical reasoners, Stanford sets the stage for a re-evaluation of our own expectations for scientists. Through the lens of epistemic responsibility, our discomfort with Stanford's historical case studies, with the limitations of past scientists, reveals our contemporary judgment that scientists (and reasoners in general) ought to reason in a way that escapes their situatedness. This type of role obligation begins to explain why realists and non-realists alike hold epistemic agents to such an impossible standard.

I will suggest that a responsibilist perspective helps to clarify the underlying force of the "new induction" and answers Stanford's critics along the way. If I am successful in this reinterpretation, then we can view Stanford's argument as an opportunity to push philosophical discourse of underdetermination in a new direction, one which has practical implications for the relation between science and society. Specifically, the existence of unconceived alternatives can motivate a broader discussion about what we, as a society, value and expect from individuals who take on the role of scientist. 
Copyright Philosophy of Science 2015

Preprint (not copyedited or formatted)

Please use DOI when citing or quoting

\section{Reformulating Underdetermination: Recent Attempts}

Stanford describes the problem of constrastive underdetermination as the worry that, even after we've successfully rejected some theories and settled on one in particular as well-confirmed, we can't be confident that the last theory standing is true. A crucial experiment or a set of failed predictions may indeed (contra confirmational holism) rule out one of two competing theories, but we cannot accept the unfalsified theory as true unless we know that it's the only remaining possibility. And there still may be equally good hypotheses that are compatible with the data, or so the worry goes.

Without the presupposition of holism, constrastive-type underdetermination relies on the assumption that empirically equivalent alternatives actually exist; we second guess the truth of our best theories only in the presence of equivalent alternatives. This, for Stanford, is where traditional arguments for contrastive underdetermination fall apart. He points out that, outside of theoretical physics, there are precious few alternate theories that are empirically equivalent to our current best theories. Sure, we can think of famous theory pairs in physics. Special relativity and Lorentz's adjusted ether theory, come to mind. Yet it is difficult to think of alternatives to the Darwinian synthesis, to the germ theory of disease, or to the particular hypothesis that influenza is caused by a viral pathogen. So it turns out that the actual science can provide only a few local cases of contrastive underdetermination. Without some additional work, one cannot claim that contrastive underdetermination is a global problem for scientific reasoning.

To remedy this practical dearth of alternative theories, some philosophers have attempted to find empirically equivalent theories algorithmically, producing what John Norton (2008) calls "artificial pairs." On the grandiose side, there are Andrè Kukla's suggestions that every theory $T$ has an alternative, "which asserts that $T$ holds whenever somebody is observing something, but that when there is no observation going on, the universe behaves in accordance with some other theory $T_{2}$ which is incompatible with $T$ " $(1996,151)$. Stanford points out that such fantastic alternatives, while perhaps philosophically serious, rely on the radically skeptical impulse that Descartes made famous. They can challenge any knowledge claim, but at the cost of losing their practical significance.

More modest algorithms for empirically equivalent alternatives focus on particular theories in science, yet fare only slightly better according to Stanford. The proponent of contrastive underdetermination might try to produce alternatives to, say, Newton's physics by considering modified versions that assign the universe a non-zero absolute velocity. Since any of these modifications are empirically untestable, we could interpret this family of related theories as providing a set of empirically equivalent theories. But that interpretation is more than the scientific realist will allow; it seems just as plausible that these alternatives are not truly different theories but really "just a single theory being conjoined with factual claims" that are untestable according to that very theory (Stanford 2006, 14). Stanford explains that this local algorithmic strategy collapses underdetermination into the well-known "tacking" 
problem in philosophy of science.

While it might be unsettling that we cannot conclusively confirm a theory against all its empirically equivalent counterparts, the apparent absence of substantive alternatives to our best scientific theories turns contrastive underdetermination into a puzzle for the armchair. Tacking claims onto a theory doesn't produce empirically equivalent theories in a way that worries scientists or even scientific realists. And to fret about, say, our current model of influenza pathology because of the mere logical possibility of an empirically equivalent alternative is tantamount to radical skepticism. It demands the same philosophical attention (or lack thereof) as brain-in-a-vat theorizing, Evil-Demon hypotheses, and the like. Unless a serious competitor appears from within the institution of science, doubts about the truth of any lone successful theory are not problems of special significance, and underdetermination loses its status as a unique problem for scientific reasoning.

\section{Stanford's "New Induction" for Contrastive Underdetermination}

There is, however, another way to motivate the worry inherent in contrastive underdetermination. Stanford proposes a "new induction" across the history of science. He attempts to show that scientifically serious alternative theories usually exist, that they are not merely skeptical reaching, and that we frequently do not conceive of them. By presenting a few cases of 19th century science, Stanford identifies a pattern in the history of scientific reasoning. Even though alternative theories are rare when we consider any one instant in history, they are plentiful from a diachronic perspective.

As Stanford explains, "past theorists repeatedly failed even to conceive of avenues of theoretical explanation for the evidence available to them that were sufficiently scientifically serious as to be actually embraced by their successors. And unless we find some reason to think that this pattern depends on idiosyncrasies of the personalities or the period involved [...then] we are in possession of a quite general challenge to scientific realism about our fundamental theories of nature" (2006, 47, emphasis mine). So much to say, unconceived yet serious alternatives are typically just a few years out of reach; whatever the reason, scientific theorizers routinely find themselves in the situation where they do not conceive of an alternative theory even though it is well-confirmed by the data on hand. And this is worrying because, in Stanford's analysis, there are no idiosyncrasies that can explain away the pattern of unconceived alternatives. In this section, I'll present this historical argument, and then consider some difficulties therein.

Stanford presents a long series of scientific shortsightedness to make his point. Charles Darwin, for instance, is described as representative of a scientific community that failed to conceive of a common cause theory of inheritance even though such a hypothesis 
would readily explain the relevant data. ${ }^{1}$ In 1868 , Charles Darwin published his own model of the mechanism of inheritance, pangenesis. The hereditary particles, "gemmules" Darwin says, are produced by every part of an organism's body, each carrying the heritable properties of the original body part. It is these particles, he explains, that are collected in the organism's gametes in order to confer the parental biological character to the offspring. This model was challenged a few years later in 1875, when Francis Galton presented an alternative theory that posited a common cause of heritable features in each generation: "stirps" are passed down from parent to child without any diffusion into other parts of the organism and produce the biological characteristics found in both parent and child generations. It is, Stanford notes, a theory that closely resembles more modern, successful germ-plasm models of inheritance.

Stanford explains that Darwin and the larger scientific community were so perplexed by Galton's common cause hypothesis, that the "stirp" theory failed to gain any credibility. But this perplexity is not the key feature of the example. Rather, we should notice, "Darwin showed no evidence of having considered and rejected the idea of a common cause rather than links in a causal chain $[\ldots]$ notwithstanding the fact that it offered equally promising strategy for explaining what he took to be the central phenomena of inheritance and generation" (2006, 75). Stanford's analysis is meant to demonstrate that Darwin and much of the scientific community failed to conceive of a serious alternative theory of inheritance for at least a decade. And as Stanford rediscovers the pattern in several other historical episodes, we are meant to see this epistemic phenomenon as frequent if not ubiquitous.

Stanford takes this recurrent shortsightedness of scientists to both explain away the present-day dearth of serious alternatives to our best theories and to reestablish the global scope of the problem of contrastive underdetermination. If we think that scientific reasoning will continue as it has in the past, then we should be distrustful of our ability to think of plausible alternative theories. Given this, our best current theory is likely to be best of only an inexhaustive set of empirically adequate theories, many of which are scientifically serious. So the global worry posed by underdetermination resurfaces. We should not trust that the data has confirmed our best current theory against alternatives. And it seems we can maintain this distrust of eliminative inferences independent of our views on confirmational holism.

\section{Strange Histories}

While Stanford's finding is striking, he seems to be committed to the existence of rather exotic scenarios in the history of science. In particular, he appears committed to the claim that at time $t_{1}$ there is an alternative theory available (though unconceived until time $t_{2}$ ) that is plausible or scientifically serious with respect to the standards of $t_{l}$. That is, after all, the condition that he thinks we might be in right now- "there are theories that we should and/or

\footnotetext{
${ }^{1}$ This episode is the subject of Chapter 3 of Exceeding Our Grasp.
} 
Copyright Philosophy of Science 2015

Preprint (not copyedited or formatted)

Please use DOI when citing or quoting

would take seriously as competitors to our best accounts of nature if we knew about them" (Stanford 2006, 23). This seems to require that unconceived alternatives, though they are chronologically distant from the context of $t_{l}$, are compatible with both the data and relevant background assumptions at $t_{l}$, whether those assumptions are methodological, metaphysical, or epistemological. Accordingly, the instances of Stanford's historical induction must be ones in which none of the relevant background assumptions changed significantly between $t_{l}$ and $t_{2}$. This historical fact, this stability in the epistemic or conceptual factors, is what makes the inconceivability so worrying. After all, if we had some explanation of the inconceivability at time $t_{l}$ (perhaps important observations had not yet been made or there are some "idiosyncrasies" in our style of reasoning), the inconceivability might reduce to the widely-recognized open character of scientific inquiry.

These cases of extended epistemic stasis are, without some qualification, quite implausible. It is unlikely that "[i]n the progression from Aristotelian to Cartesian to Newtonian to contemporary mechanical theories, for instance, the evidence available at the time each earlier theory dominated the practice of its day also offered compelling support for each of the later alternatives (unconceived at the time)" (Stanford 2013). Presumably, Newtonians could have had background assumptions (not to mention different data or pragmatic constraints) that prevented them from even considering relativistic mechanics. In other words, it seems unlikely that the choice between Newtonian and relativistic mechanics was really underdetermined prior to the conception of the latter theory. And critics of Exceeding Our Grasp have said as much. P.D. Magnus (2006) points out that the move away from Newtonian physics involved not only old data but also new findings incompatible with the old paradigm, meaning that Einstein and Newton are not on "equal footing." Along similar lines, Winther (2009) invokes a frustrated constructivist who laments the text's complete lack of consideration of the ways in which humans are pragmatically and cognitively constrained. Saatsi (2009), finally, wonders why we should worry about the counterfactual availability of an unconceived alternative to a historical figure rather than its availability to the entire community of inquiry.

These criticisms, requests for more contextual details, threaten the relevance and novelty of the Stanford's argument. Magnus concludes that since the respectability of a theory is a contextual matter, any instances of the new induction must take this into account. Else, the new induction risks collapsing into an old problem of induction. Stanford must show, Magnus explains, that Kant did not have contextual reasons to consider only Newtonian mechanics (i.e. he must show that the choice was indeed underdetermined). If Stanford ignores these contextual elements and simply asserts that the data (in isolation) equally confirm both theories, then he is not making a distinct point from the Grue paradox-Stanford is simply asserting that the data could have confirmed a theory that wasn't scientifically serious at the time, now a well-known possibility in the confirmation literature. As Magnus says, "If there is no way to decide against grue-like hypotheses, then scientific theory choice would be impossible - but that's old news" $(2006,299)$. If relativistic mechanics is to be part 
of a scenario of worrying underdetermination (rather than a type of Grue paradox), it must be scientifically serious by Kant's standards.

Stanford's reply to these criticisms is two-fold. First, he takes himself to have avoided the issue of changing scientific or cultural norms by limiting his instances to a narrow range of times and people, a single "shared" context (Stanford 2009). Yet this narrow locus of study does not obviously answer Stanford's critics. Assume that we grant the historical assertion: Darwin and his colleagues, for at least a decade, had all the requisite data and background assumptions that would make a common cause theory of inheritance a serious consideration and that when Galton finally did propose it, the conceivability wasn't due to some metaphysical or epistemological assumption being relaxed. I will tentatively accept this claim, as I am not an historian equipped to challenge it. My worry here reasserts that of Magnus and Saatsi, but on a smaller scale. Since Stanford declines to explain what actually caused the inconceivability of common cause inheritance (for Darwin), it's not immediately clear why the episode is troubling. Without some story about what exactly limited Darwin, it seems that we should hesitate to label the instance as worrisome. It may well be that Darwin was afflicted with some personal source of bias that did not affect his scientific community of peers. Or maybe, there were local socio-political reasons for the inconceivability. So why should we worry about this as a case of underdetermination?

The second aspect of Stanford's reply goes some way to answer this question, and to "evade the need to debate any claim of relative fixity or privilege for relevant features of our own cultural and scientific context" (Stanford 2009, 382). Stanford states that, even if the recurrent inconceivability of scientifically serious alternatives is explainable by particular contextual constraints, the anti-realist thrust of the new induction survives. Regardless of which explanation we might give, the new induction still suggests that there are scientifically serious alternative theories that we are currently not considering due to our own current scientific or cultural contextual constraints, whatever those are. In other words, if Stanford's primary historical argument buckles under pressure from constructivists and contextually-savvy realists, he can still provide a version that will satisfy them and prove the same point. Nevertheless, Stanford explains, he chose not to pursue this line of argument in order to avoid tying his project to any particular story about how context constrains conceivability.

But in this reply, Stanford misses an opportunity to address the underlying intuition that drives his new induction. He never explains why, once we've assumed a constructivist picture of knowledge, we should care about particular failures to conceive of alternative theories or why we should worry about the limitations of a single theorist. If we understand the situated character of our predecessors' reasoning, then we see that their knowledge isn't the sort of thing that can be compared diachronically with ours. Put slightly differently, Stanford does not give us a detailed account of why anyone (realist or constructivist) would encourage or even allow anachronistic analyses of the beliefs of historical figures. 
Copyright Philosophy of Science 2015

Preprint (not copyedited or formatted)

Please use DOI when citing or quoting

\section{On the Epistemic Obligations of Scientists}

How then do we understand this whiggish impulse to worry about the explainable epistemic behavior of past scientists? Surely the existence of unconceived alternatives would not be particularly upsetting to a careful historian or sociologist of science. One answer can be found in the traditional worries about realism. We might, as philosophers tend to, be driven by worries about our ability to access objective reality, to collect mind-independent and culture-independent truths about the world. I interpret Stanford's book as problematizing this impulse. But presumably not everyone who is worried about epistemic limitations is driven by worries about our best theories being true of the world. The more general force of the "new induction," I suggest, can be productively understood in terms of responsibilist epistemology and deontological judgments about beliefs.

Lorraine Code (1987) and Richard Feldman (2000), among others, explore the possibility of understanding epistemic justification in terms of deontological judgments. They note that we do often judge the beliefs of others, using the vocabulary of praise and blame, rights and duties. A primary obstacle to this type of account, however, is the possibility that individuals cannot fully control what they believe (i.e. doxastic involuntarism). And if people cannot voluntarily adjust their own states of belief, it seems nonsensical to say that they are obligated to believe some things but not others. "Ought", after all, usually implies "can." Feldman's solution, here, is particularly relevant for understanding Stanford's induction and for quelling the disapproval of his critics.

Feldman suggests that we might have epistemic obligations even if we are unable to fulfill those obligations. This sort of duty is not without precedent, he suggests. Contractual obligations, he notes, are obligations that we have despite our inability to fulfill them; I ought to pay my rent, for example, even if I'm unable to do so. My contract with my landlord is binding, regardless of the status of my bank account. Most relevant to Stanford's argument, Feldman also introduces the idea of "role oughts," obligations we have in virtue of a role that we fill. Professors, for instance, ought to frequently check-in with their graduate students, though they might be unable to do so because of time constraints. Physicians ought to carefully weigh all of the potential treatments for their patients, even though long working hours at the hospital might prevent them from thinking clearly.

In instances of either contractual obligations or role oughts, we expect individuals to fulfill the obligations of their roles or contracts, simply in virtue of taking on some role or assenting to some contract. This fact suggests a new way to understand epistemic obligations. To complete his particular argument, Feldman invokes the rather dramatic role of the knower (2000, 684). As knowers, he suggests, individuals might have certain epistemic obligations that are, strictly speaking, beyond their ability to fulfill. This is a powerful insight, but the rather broad role of knower suggests equally broad responsibilities, like the responsibility to believe what is supported by one's available evidence.

Code, however, suggests a slightly narrower scope for epistemologically significant 
roles. She explains that epistemic obligations, like any other obligation, originate in one's membership in particular communities $(1987,44)$. Thus, one might have epistemic obligations in virtue of being a natural philosopher or a scientific theorist. Drawing Code and Feldman's insights together, I suggest that we recognize that scientists, including those in Stanford's work, might have their own unique role oughts, some of which are epistemic in nature. A general explication of these duties would require its own paper, but for my purposes here I suggest at least one obligation that seems implicit in the "new induction": scientists ought not believe a theory on the basis of a contextually-contingent eliminative inference. In other words, the scientist should be able to distinguish between two scenarios: 1) situations where the last theory standing is, in all contexts, the only theory that explains the evidence and 2) situations where the last theory standing is the last theory only because some contextual feature prevents scientists from conceiving of genuine alternatives.

Notice that fulfilling this obligation requires, quite improbably, that scientists escape any contextually-contingent constraints on their reasoning, including cultural assumptions, implicit bias, psychological limitations, and so on. If Feldman is correct, however, the simple inability of scientists to fully evade their situatedness does not entail that they have no obligation to do so. Accordingly, I suggest that it is this role ought that motivates us to criticize past scientists for their failure to see their own contextual limitations, regardless of our particular stance on scientific realism. If I'm correct in this interpretation, we have a new way to understand seemingly ahistorical assessments of past science, including both Stanford's new induction and feminist critiques of science.

We can, then, draw interesting parallels between the critical mode of engagement present in many feminist critiques and Stanford's use of counterfactual judgments about the availability of unconceived alternatives. When Anne Fausto-Sterling (1992), for example, criticizes research programs that rely on androcentric values, she need not prove counterfactually that scientists really could have relied on a different, non-sexist background assumption. It does not matter that those researchers might have been constrained by their place in society or within the institutional structure of science. Unlike descriptive analyses of historical scientists, this engagement is normative, meaning that it's acceptable to imply that researchers should have considered other values (regardless of the ways that they were contextually constrained). Similarly, when Stanford shows that an alternative was available to Darwin, "available" is relative to a restricted set of factors that Stanford thinks should be sufficient for scientific reasoning. In other words, the determination of which theoretical alternatives are available to a historical figure is determined as much by the critic's evaluation of what scientific practice requires as it is determined by descriptive historical scholarship.

Returning to the misgivings of Stanford's critics, we can now explain Stanford's controversial use of history. Recall that Stanford's critics were confused by the fact that his inductive instances of historical underdetermination rely on an implicit judgment about the availability of genuine, non-skeptical unconceived alternatives. Surely a contextually-sensitive history would not reveal any actual underdetermination, they seem to 
Copyright Philosophy of Science 2015

Preprint (not copyedited or formatted)

Please use DOI when citing or quoting

suggest. And it was simply not clear what allows Stanford to delimit the scope of his historical analysis in order to establish that an unconceived alternative would have been a serious candidate had it been considered by the individual theorist. By acknowledging the deontological underpinnings of the "new induction," we can assuage these worries. Specifically, we can interpret Stanford's analyses of past research (e.g. that Darwin ought to have thought of the alternative mode of gemmules diffusions, that Kant ought to have considered relativistic physics) in terms of backwards-looking normative judgments. Though they originate in the norms of a community, we impose these epistemic obligations on individuals, on anyone who appears to take on the role of scientist.

Hopefully, this new framing is not so implausible; it seems reasonable to assert that Stanford and feminist philosophers alike participate in a tradition in which there are standards according to which a scientist might believe well, or reason well. After all, such a normative impulse seems to run throughout twentieth century philosophy of science, through operationalism, critical rationalism, and the debate over the role of values in science.

Scientists are expected to make responsible use of concepts, constantly test their theoretical commitments, and transcend their cultural context. So perhaps, in applying the "new induction," we judge past scientists' reasoning in the same way that we judge the conduct of a physician or of a police officer; we hold them accountable to the obligations of their role, regardless of their own (possibly unavoidable) limitations. If we interpret Stanford's argument in this way, acknowledging the contemporary source of his normative claims, the criticisms directed at Stanford's induction (by Magnus and others) aren't nearly as troubling.

\section{A New Way Forward for Contrastive Underdetermination}

In conclusion, I'd like to suggest that a deontological framework for epistemic justification gives us a new way to understand contrastive underdetermination and its basis in Stanford's induction. While Stanford uses his induction to worry scientific realists, its core impulse is an expectation that is shared more widely than simply among realists. Many people expect, rather quixotically, that good scientific reasoning should remain valid across all possible contexts and cultures. Accordingly, when Stanford ignores the effect of context and other factors ("idiosyncrasies") in order to demonstrate the existence of unconceived alternatives, he is not doing poor history or simply relying on realist assumptions. He is leveraging our contemporary understanding of the duties of scientists. Consequently, if there is a broader lesson to be learned from contrastive underdetermination, it is that our characterization of the ideal scientist is in direct tension with the situated reality of reasoning.

What we make of this tension between duties and reality is, of course, up to us. We could, stubbornly, use examples like those of Stanford to blame past scientists for their 
Copyright Philosophy of Science 2015

Preprint (not copyedited or formatted)

Please use DOI when citing or quoting

shortsightedness. Such judgment may be appropriate at times. At the other extreme, the new induction might suggest reflection on and even revision of the duties that we impose on them. Either way, Stanford's updated argument for constrastive underdetermination embodies a particular ethics of belief, one which deserves further scrutiny. A responsibilist perspective, thus, helps explain how underdetermination (and perhaps other puzzles in philosophy of science) can be worrying despite practical irrelevance. One does not frequently find scientists epistemically paralyzed, afraid to make eliminative inferences for fear of being contextually constrained, and we may be tempted to dismiss underdetermation as a philosopher's puzzle, suitable only for the armchair. A responsibilist perspective, to the contrary, suggests that we view contrastive underdetermination as a result of the duties of the scientist in contemporary Western culture. This presents philosophers of science, and society at large, with an opportunity to re-evaluate, carefully: "what do we value in a scientist and why?" 
Copyright Philosophy of Science 2015

Preprint (not copyedited or formatted)

Please use DOI when citing or quoting

\section{References}

Code, Lorraine. 1987. Epistemic Responsibility. Hanover: University Press of New England. Fausto-Sterling, Anne. 1992. Myths of Gender: Biological Theories about Women and Men. New York: Basic Books.

Feldman, Richard. 2000. "The Ethics of Belief." Philosophy and Phenomenological Research 60(3): 667-695.

Kukla, Andre. 1996. "Does Every Theory Have Empirically Equivalent Rivals?". Erkenntnis, 44(2), 137-166.

Magnus, P.D. 2006. "What's New about the New Induction?" Synthese, 148(2), 295-301.

Norton, J. D. 2008. "Must Evidence Underdetermine Theory." in The Challenge of the Social and the Pressure of Practice: Science and Values Revisited. Carrier, Howard, and Kourany eds., Pittsburgh: University of Pittsburgh Press, 17-44.

Saatsi, Juha. 2009. "Grasping at Realist Straws: Review Symposium", Metascience, 18(3), $355-390$.

Stanford, Kyle. 2006. Exceeding Our Grasp: Science, History, and the Problem of Unconceived Alternatives. New York: Oxford University Press.

— 2009. "Author's Response" in "Grasping at Realist Straws: Review Symposium", Metascience, 18(3), 355-390.

- 2013. "Underdetermination of Scientific Theory" Stanford Encyclopedia of Philosophy (Winter 2013 edition). Edward N. Zalta (ed.). Accessed February 28, 2014. http://plato.stanford.edu/archives/win2013/entries/scientific-underdetermination/

Winther, Rasmus G. 2009. "A Dialogue" in "Grasping at Realist Straws: Review Symposium", Metascience, 18(3), 355-390. 